\title{
Treatment for Congenital Cytomegalovirus Infection: who, for how long, with what Drug Regimen?
}

\section{Bernhard Resch*}

Department of Paediatrics, Medical University of Graz, Austria

Congenital cytomegalovirus (CMV) infection is the most frequently identified viral cause of mental retardation and is the leading non-genetic cause of neurosensory hearing loss in developed countries, and is the most common congenital infection in human beings, with approximately $1 \%$ of all infants born alive in the United States being infected with CMV [1-3]. Infants with symptomatic CMV infection with observations at birth including petechiae, hepatosplenomegaly, microcephaly, thrombocytopenia, or jaundice with conjugated hyperbilirubinemia showed in $70 \%$ of cases abnormal computed tomographic (CT) scans with intracerebral calcification being the most frequent finding, and again $90 \%$ of the children with an abnormal newborn CT scan developed at least one sequela [4]. In addition, almost half of the children with CT abnormalities had an IQ $<50$ compared with none of those with a normal CT. Of infected fetuses, approximately $10 \%$ are symptomatic at birth, and $90 \%$ of symptomatic survivors have significant neurologic sequelae, including hearing deficits in $30 \%$ to $65 \%[5,6]$.

CMV load in cord vein blood was found to be significantly lower than that in urine, thus, the CMV load in urine seems to reflect organ involvement and effect of therapy best. Nevertheless, determination of CMV DNA in cord vein blood is the most rapid diagnostic test for congenital CMV infection [7].

There are currently four antiviral drugs licensed for the treatment of CMV infections: ganciclovir (GCV), valganciclovir (VGCV), foscarnet (FOS), and cidofovir (CDV) $[8,9]$. These drugs have provided major advances in CMV disease management, although they are limited by intolerable toxicities, oral bioavailability and efficacy, and risk of drug resistance with extended use.

Searching for evidence based or scientific guidelines for selection of newborns with congenital CMV infection that might benefit from treatment with ganciclovir Smets et al. [10] identified 13 case reports (16 patients in all), three descriptive uncontrolled studies (20 patients in all), two randomized dose-comparative studies (54 patients in all) and one randomized controlled study (42 patients) with all patients presenting with central nervous system (CNS) manifestation of CMV infection. Kimberlin and co-workers [11] published the only prospective randomized controlled study by enrolment of 100 infants from 18 US centres between 1991 and 1999. Infants $\leq 1$ month of age, $\geq$ 32 weeks' gestation, and weighing $\geq 1200 \mathrm{~g}$ at birth having evidence of CNS disease, such as (1) microcephaly; (2) intracranial calcifications; (3) abnormal cerebrospinal fluid for age; (4) chorioretinitis; and/ or (5) hearing deficits were eligible for study participation. Patients were randomly assigned to receive ganciclovir treatment $(6 \mathrm{mg} / \mathrm{kg}$ per dose administered intravenously every 12 hours for 6 weeks) or no treatment. Of these, 42 patients had both a baseline and 6-month follow-up audiometric examination and thus were evaluable for the primary end point (improved brainstem-evoked response, BERA). Twenty-one (84\%) of 25 ganciclovir recipients had improved hearing or maintained normal hearing between baseline and 6 months versus $10(59 \%)$ of 17 control patients $(\mathrm{p}=.06)$. None $(0 \%)$ of 25 ganciclovir recipients had worsening in hearing between baseline and 6 months versus $7(41 \%)$ of 17 control patients $(\mathrm{p}<.01)$. The authors concluded that ganciclovir therapy having begun in the neonatal period in symptomatically infected infants with CMV infection involving the CNS prevents hearing deterioration at 6 months and may prevent hearing deterioration at $\geq 1$ year. The most common side effect of ganciclovir therapy was significant neutropenia in almost two thirds of treated infants during therapy. Six years following the publication of this trial the group published the impact of ganciclovir therapy on neurodevleopmental outcomes (Oliver 2009) and found fewer developmental delays at 6 and 12 months ( $\mathrm{p}=.02$ and .007 , respectively). The authors claimed that data cannot be extrapolated to neonates with other manifestations of CMV disease including asymptomatic babies and symptomatic babies who do not have CNS involvement.

On the basis of the above mentioned study a target AUC12 (area under the concentration-time curve over a 12-h period) of $27 \mathrm{mg} \mathrm{X} \mathrm{h/L}$ was defined in a prospective pharmacokinetic and pharmacodynamic study of the use of valganciclovir in symptomatic CMV disease [12]. The median dose of oral valganciclovir administered was $16 \mathrm{mg} / \mathrm{kg}$, which produced a geometric mean AUC12 of $27.4 \mathrm{mg} \mathrm{X} \mathrm{h/L} \mathrm{with} \mathrm{a}$ bioavailability of $41.1 \%$. Interestingly, infants who started the study with higher viral burden experienced greater decreases in viral load but did not clear virus during the 42-day course of therapy. Neutropenia developed in $38 \%$ of subjects; that was markedly lower compared to ganciclovir with $64 \%$.

Uncontrolled case series advocate a more prolonged course of therapy for optimal outcome, partially with oral valganciclovir and apparently without higher risk of side effects [13-16]. Divergent regimens of oral valganciclovir therapies in symptomatic [17-25] and even asymptomatic $[26,27]$ cases of congenital CMV infection were reported more recently. A multi-centre, prospective, international, phase III, randomized and blinded investigation of six weeks versus six months of oral valganciclovir therapy in babies with symptomatic congenital CMV disease is currently underway [28]. At this time, however, by lack of controlled trials, there is no real evidence for longer treatment.

The major benefit from ganciclovir or valganciclovir treatment in infants with congenital CMV might be a preservation of hearing, at least in the intermediate term. Smets and the working goup members [10] felt that newborns with severe hearing loss who repeatedly reach thresholds of $\geq 100 \mathrm{~dB}$ at BERA audiometry should not be treated

*Corresponding author: Bernhard Resch, Research Unit for Neonatal Infectious Diseases and Epidemiology, Division of Neonatology, Department of Paediatrics, Medical University of Graz, Austria, Tel: +43-316-385-81134; Fax: +43-318-385 12678; E-mail: Bernhard.resch@medunigraz.at

Received June 20, 2012; Accepted June 21, 2012; Published June 24, 2012

Citation: Resch B (2012) Treatment for Congenital Cytomegalovirus Infection: who for how long, with what Drug Regimen? J Neonatal Bio 1:e105. doi:10.4172/2167$0897.1000 \mathrm{e} 105$

Copyright: (C) 2012 Resch B. This is an open-access article distributed under the terms of the Creative Commons Attribution License, which permits unrestricted use, distribution, and reproduction in any medium, provided the original author and source are credited. 
Citation: Resch B (2012) Treatment for Congenital Cytomegalovirus Infection: who, for how long, with what Drug Regimen? J Neonatal Bio 1:e105. doi:10.4172/2167-0897.1000e105

Page 2 of 2

with ganciclovir. They argue that even with some improvement in hearing abilities, these infants are very likely to need cochlear implants anyway. Smets et al. would recommend inclusion of babies with CNS manifestations of CMV infection (excluding isolated striatal vasculopathy and isolated single periventricular pseudocyst) and newborns with growth retardation and/or petechiae for ganciclovir therapy. The authors although advocated that there is no literature data on treatment of asymptomatic children; this should only be done within the setting of a clinical trial, and such trials should preferably include asymptomatic babies with high viral load, as they are at higher risk of hearing loss.

More recent evidence based management guidelines for the treatment of congenital CMV infection are based on the decision whether the baby is asymptomatic or symptomatic, and the latter is defined as CNS symptomatic disease (as described above) and severe focal organ disease including severe hepatitis, severe bone marrow suppression (all three cell lines), colitis or pneumonitis [29]. In their management algorithm for the treatment of congenital CMV the authors recommend a six weeks course of either intravenous ganciclovir or oral valganciclovir with dosage regimens as described above. All asymptomatic or mild to moderate symptomatic infants with congenital CMV infection should not receive treatment. A close follow-up of all infants whether treated or not is mandatory.

In conclusion there is still lack of evidence on successful antiviral treatment of symptomatic congenital CMV infection especially regarding long-term positive effects on either hearing or neurodevelopmental impairment beyond the first year of age. Oral valganciclovir therapy seems to be as effective as intravenous ganciclovir during a six weeks course of treatment. The effects of longer courses of oral valganciclovir treatment have still to be evaluated and results of the CASG trial have to be awaited until further recommendations can be given.

\section{References}

1. Demmler GJ (1991) Infectious Diseases Society of America and Centers for Disease Control. Summary of a workshop on surveillance for congenital cytomegalovirus disease. Rev Infect Dis 13: 315-329.

2. Fowler KB, Stagno S, Pass RF, Britt WJ, Boll TJ, et al. (1992) The outcome of congenital cytomegalovirus infection in relation to maternal antibody status. N Engl J Med 326: 663-667.

3. Fowler KB, McCollister FP, Dahle AJ, Boppana S, Britt WJ, et al. (1997) Progressive and fluctuating sensorineural hearing loss in children with asymptomatic congenital cytomegalovirus infection. J Pediatr 130: 624-630.

4. Boppana SB, Fowler KB, Vaid Y, Hedlund G, Stagno S, et al. (1997) Neuroradiographic findings in the newborn period and long-term outcome in children with symptomatic congenital cytomegalovirus infection. Pediatrics 99: 409-414.

5. Pass RF, Stagno S, Myers GJ, Alford CA (1980) Outcome of symptomatic congenital cytomegalovirus infection: results of long-term longitudinal followup. Pediatrics 66: 758-762.

6. Pass RF, Fowler KB, Boppana SB, Britt WJ, Stagno S (2006) Congenital cytomegalovirus infection following first trimester maternal infection: symptoms at birth and outcome. J Clin Virol 35: 216-220.

7. Halwachs-Baumann G, Genser B, Pailer S, Engele H, Rosegger H, et al. (2002) Human cytomegalovirus load in various body fluids of congenitally infected newborns. J Clin Virol 25: S81-S87.

8. Biron KK (2006) Antiviral drugs for cytomegalovirus diseases. Antiviral Res 71: $154-163$

9. Ahmed A (2011) Antiviral treatment of cytomegalovirus infection. Infect Disord Drug Targets 11: 475-503.

10. Smets K, De Coen K, Dhooge I, Standaert L, Laroche S, et al. (2006)
Selecting neonates with congenital cytomegalovirus infection for ganciclovir therapy. Eur J Pediatr 165: 885-890.

11. Kimberlin DW, Lin C-Y, Sanchez PJ, Demmler GJ, Shelton M, et al. (2003) Effect of ganciclovir therapy on hearing in symptomatic congenital cytomegalovirus disease involving the central nervous system: a randomized controlled trial. J Pediatr 143: 16-25.

12. Kimberlin DW, Acosta EP, Sánchez PJ, Sood S, Agrawal V, et al. (2008) Pharmacokinetic and pharmacodynamic assessment of oral valganciclovir in the treatment of symptomatic congenital cytomegalovirus disease. J Infect Dis 197: 836-845.

13. Nigro G, Scholz H, Bartmann U (1994) Ganciclovir therapy for symptomatic congenital cytomegalovirus infection in infants: a two-regimen experience. $J$ Pediatr 124: 318-322.

14. Michaels MG, Greenberg DP, Sabo DL, Wald ER (2003) Treatment of children with congenital cytomegalovirus infection with ganciclovir. Pediatr Infect Dis J 22: 504-509.

15. Rojo P, Ramos JT (2004) Ganciclovir treatment of children with congenital cytomegalovirus infection. Pediatr Infect Dis J 23: 88-89.

16. Burri M, Wiltshire H, Kahlert C, Wouters G, Rudin C (2004) Oral valganciclovir in children: single dose pharmacokinetics in a sixyear- old girl. Pediatr Infect Dis J 23: 263-266

17. Meine Jansen CF, Toet MC, Rademaker CM, Ververs TF, Gerards LJ, et al. (2005) Treatment of symptomatic congenital cytomegalovirus infection with valganciclovir. J Perinat Med 33: 364-366.

18. Galli L, Novelli A, Chiappini E, Gervaso P, Cassetta MI, et al. (2007) Valganciclovir for congenital $\mathrm{CMV}$ infection: A pilot study on plasma concentration in newborns and infants. Pediatr Infect Dis J 26: 451-453.

19. Müller A, Eis-Hübinger AM, Brandhorst G, Heep A, Bartmann P, et al. (2008) Oral valganciclovir for symptomatic congenital cytomegalovirus infection in an extremely low birth weight infant. J Perinatol 28: 74-76.

20. Hilgendorff A, Daiminger A, Dangel V, Kreuder J, Geidel C, et al. (2009) Oral Valganciclovir treatment in a CMV congenital infected infant with sensorineural hearing loss (SNHL) first detected at 4 months of age. Klin Padiatr 221: 448-449

21. Baquero-Artigao F, Romero Gómez MP (2009) Prolonged treatment with valganciclovir in an infant with congenital cytomegalovirus infection. An Pediatr (Barc) 70: 578-581

22. Lombardi G, Garofoli F, Villani P, Tizzoni M, Angelini M et al. (2009) Oral valganciclovir treatment in newborns with symptomatic congenital cytomegalovirus infection. Eur J Clin Microbiol Infect Dis 28: 1465-1470

23. Amir J, Wolf DG, Levy I (2010) Treatment of symptomatic congenital cytomegalovirus infection with intravenous ganciclovir followed by long-term oral valganciclovir. Eur J Pediatr 169: 1061-1067.

24. Imamura T, Suzutani T, Ogawa H, Asano K, Nomoto M et al. (2011) Ora valganciclovir treatment for congenital cytomegalovirus infection. Pediatr Int 32: $249-252$.

25. Irizarry K, Honigbaum S, Demmler-Harrison G, Rippel S, Wilsey M Jr (2011) Successful treatment with oral valganciclovir of primary CMV enterocolitis in a congenitally infected infant. Fetal Pediatr Pathol 30: 437-441.

26. Stronati M, Garofoli F, Angelini M, Licari A, Manzoni P, et al. (2011) Valganciclovir treatment in a 6-month-old infant with asymptomatic congenital cytomegalovirus infection and late hearing loss. Pediatr Infect Dis J 30: 11241125.

27. Yilmaz Çiftdogan D, Vardar F (2011) Effect on hearing of oral valganciclovir for asymptomatic congenital cytomegalovirus infection. J Trop Pediatr 57: 132-134.

28. http://medicine.uab.edu/Peds/CASG/75323/

29. Kadambari S, Williams EJ, Luck S, Griffiths PD, Sharland M (2011) Evidence based management guidelines for the detection and treatment of congenital CMV. Early Hum Dev 87: 723-728. 